\title{
The Economic Burden of Lupus Nephritis: A Systematic Literature Review
}

Juliette C. Thompson · Anadi Mahajan · David A. Scott •

Kerry Gairy (1)

Received: May 7, 2021 / Accepted: August 27, 2021 / Published online: November 3, 2021

(c) The Author(s) 2021

\begin{abstract}
Introduction: Few studies have evaluated the economic burden of lupus nephritis (LN). The aim of this systematic literature review (SLR) was to assess the economic burden (direct and indirect costs, and healthcare resource utilization [HCRU]) associated with $\mathrm{LN}$, with particular focus on the burden of renal flares and end-stage kidney disease (ESKD).

Methods: This SLR (GSK study 213531) was conducted and reported according to the Preferred Reporting Items for Systematic Reviews and Meta-Analyses guidelines. Searches of the MEDLINE and Embase databases were conducted for English language publications reporting cost or HCRU data in patients with LN (regardless of age or LN histological class) until
\end{abstract}

Supplementary Information The online version contains supplementary material available at https:// doi.org/10.1007/s40744-021-00368-y.

J. C. Thompson · A. Mahajan · D. A. Scott

Bridge Medical Consulting Ltd, 2 Marsault Court, 11

Kew Foot Road, Richmond, London TW9 2SS, UK

J. C. Thompson · D. A. Scott

Visible Analytics Ltd, 3 Kings Meadow, Oxford OX2 ODP, UK

K. Gairy $(\bowtie)$

Value Evidence and Outcomes, GlaxoSmithKline, 980 Great West Road, Brentford, Middlesex TW8 9GS, UK

e-mail: kerry.x.gairy@gsk.com
December 10, 2019. Handsearching of conference proceedings and keyword-based searches in PubMed, Google, and Google Scholar were also conducted.

Results: Twenty-two studies were identified from 28 publications reporting the cost $(n=19)$ and HCRU $(n=13)$ associated with LN. Most studies were from North America $(n=13)$ and many used administrative claims data $(n=9)$. LN was associated with substantially higher direct costs (e.g., total annual, hospitalization, and ESKD-related direct costs), total indirect costs, and HCRU (e.g., hospitalization, outpatient services, and medication use) compared with patients without systemic lupus erythematosus (SLE) or non-renal SLE controls. ESKD and dialysis were significant contributors to economic burden. No studies described the cost of renal flares.

Conclusions: The consensus across the 22 studies was that the economic burden of $\mathrm{LN}$ is substantial, particularly in active or severe disease, or if there is progression to ESKD. Total direct cost may be underestimated in claims data given the challenges of identifying patients with LN. Further studies are vital to ascertain the cost of renal flares; a renal flare is likely to result in a period of increased HCRU, which could be mitigated by treatments that extend renal remission. 
Keywords: Cost; Economic burden; Lupus nephritis; Systematic literature review; Systemic lupus erythematosus

\section{Key Summary Points}

The objective of this systematic literature review was to assess the economic burden (direct and indirect costs, and healthcare resource utilization [HCRU]) associated with lupus nephritis (LN), with a specific focus on the costs and HCRU associated with renal flares and end-stage kidney disease (ESKD).

LN was associated with substantially higher direct and indirect costs and HCRU compared with patients without systemic lupus erythematosus (SLE) or non-renal SLE control populations.

The largest gap in the literature is for HCRU and cost data characterizing a renal flare in patients with LN; a flare is likely to result in a period of increased HCRU and therefore optimal management and minimization of flares (i.e., maintaining renal remission) would reduce overall costs.

There are also limited cost and HCRU data on patients with LN and ESKD; presenting challenges for cost-effectiveness analysis where most data were derived from a nonSLE chronic kidney disease population.

\section{INTRODUCTION}

Systemic lupus erythematosus (SLE) is a chronic, multisystem autoimmune disease that predominantly affects women of child-bearing age [1]. It is characterized by abnormal B-cell and T-cell activation and the generation of pathogenic autoantibodies $[2,3]$. The resulting inflammation and subsequent damage of tissue and organs underpin the diverse range of debilitating clinical manifestations associated with the disease [3].

Approximately $31-48 \%$ of patients with SLE develop lupus nephritis (LN), the most severe organ manifestation of SLE, with $7-31 \%$ of patients being diagnosed with LN at SLE diagnosis [4-7]. Patients with LN have a higher risk of death compared with the general population, a risk that increases further if LN progresses to end-stage kidney disease (ESKD) [8]. Overall, up to $28 \%$ of patients with $\mathrm{LN}$ will subsequently develop ESKD, with a cumulative incidence ranging from 6-19\% over 10 years [4]. Thus, the spectrum of LN includes patients with a range of clinical severities and therefore economic burden.

A single LN renal flare can reduce the glomerular filtration rate by approximately $40 \%$ and usually results in irreversible nephron loss that shortens kidney lifespan by decades [7]; as such, prevention of renal flares, or put conversely, the maintenance of renal remission, is a critical long-term treatment goal. As well as the clinical impact of renal damage, chronic kidney disease (CKD; not specific to $\mathrm{LN}$ ) has been shown to significantly increase all-cause costs compared with those in patients without CKD [9]. This highlights the additional economic importance of preventing deterioration of renal function in LN. Patients with LN are also more likely to develop cardiovascular comorbidities than patients with SLE who do not have LN [10], which has been shown to increase the annual total costs of SLE by a factor of 2.3 [11]. Finally, risk of infection in SLE is increased by both disease activity (including renal involvement) and immunosuppressive treatment $[7,12]$. Serious infections in SLE were found to increase hospitalization rates by up to 24 times compared with those in patients without SLE [13], which would likely result in substantially higher direct costs.

There is a high economic burden on the healthcare system associated with the management of patients with SLE, with mean annual direct and indirect cost ranges of 
US\$2214-16,875 and US\$2239-35,540, respectively $[14,15]$. In patients with SLE, pharmaceutical costs accounted for $19-30 \%$ of total expenditures; and inpatient and outpatient costs composed $16-50 \%$ and $24-56 \%$ of overall costs, respectively [14]. However, higher costs have been reported for patients with LN [14, 16], with a mean annual direct cost range of US\$29,034-\$62,651 [14]. Increased disease activity and organ damage have also been shown to increase costs in patients with SLE [17-20]. Despite this, few studies have evaluated the economic burden of the subgroup of patients with LN.

Given the emergence of new treatments for LN $[21,22]$, there is a renewed need to evaluate and summarize the direct (e.g., hospitalization, outpatient visits, diagnostics, and medications) and indirect (e.g., lost productivity and absenteeism) costs and healthcare resource utilization (HCRU) associated with $\mathrm{LN}$ to inform efficient resource allocation in future clinical practice.

Accordingly, the objective of this systematic literature review (SLR) was to assess the economic burden associated with $\mathrm{LN}$, with a particular focus on the costs and HCRU related to renal flares and ESKD.

We aimed to answer two specific research questions:

1. What are the direct and indirect costs associated with LN?

2. How does LN impact HCRU?

\section{METHODS}

\section{Search strategy}

In this study (GSK study 213531), a systematic literature search was conducted to identify publications reporting either cost or HCRU data in patients with LN (regardless of age, method of diagnosis, or LN histological class). Structured searches using indexed and free-text terms were conducted in MEDLINE and Embase from database inception to December 10, 2019. Both databases were searched via the Embase.com interface, using the specific disease and economic burden facets designed when developing the search strategy. The final search strategy is detailed in Supplementary Table 1. Handsearching of conferences proceedings (2017-2019) and keyword-based searches in PubMed, Google, and Google Scholar were also conducted to retrieve relevant evidence (Supplementary Methods).

\section{Eligibility criteria and article selection}

Screening of both title/abstract and full publication text was conducted by two independent reviewers in accordance with the Preferred Reporting Items for Systematic Reviews and Meta-Analyses (PRISMA) guidelines [23-25]; any disagreements were resolved by a third reviewer. Publications were included that met the predefined eligibility criteria summarized in Supplementary Table 2 .

\section{Data analysis and presentation}

Direct and indirect costs associated with LN were stratified by disease stage and country, where possible. The impact of LN on HCRU was assessed by the frequency of hospitalizations and outpatient visits, and medication use. No quantitative synthesis was planned; the outcomes of this SLR are descriptive.

\section{Ethics compliance}

This article is an SLR of published articles and does not report a study conducted by the authors involving human participants or animals.

\section{RESULTS}

\section{Study selection and characteristics}

As shown in the PRISMA flow diagram (Fig. 1), 22 studies from 28 publications published between 2007 and 2019 were identified, which provided information on the cost $(n=19)$ and HCRU $(n=13)$ associated with LN [26-47]. 


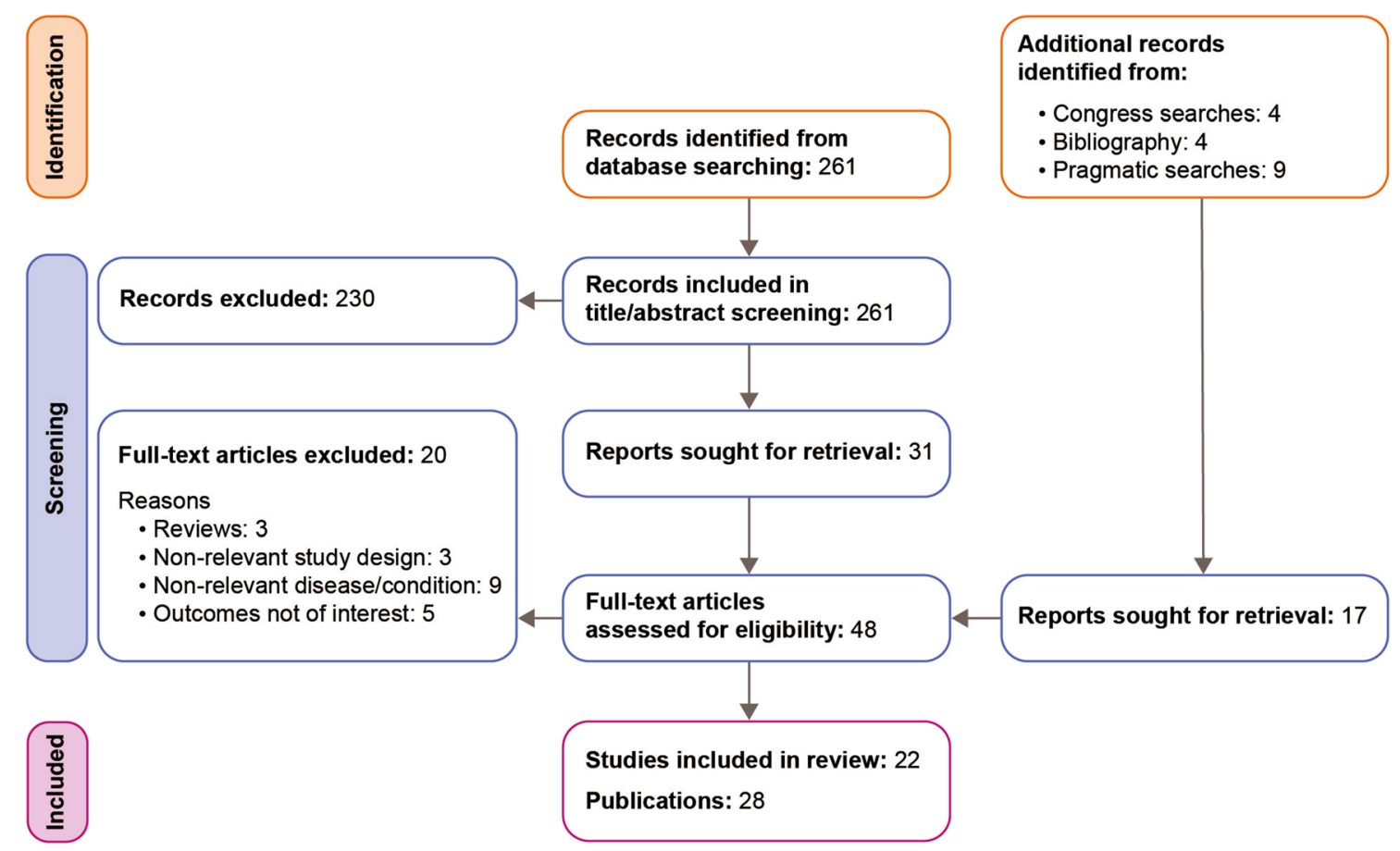

Fig. 1 PRISMA (Preferred Reporting Items for Systematic Reviews and Meta-Analyses) flow diagram

Study characteristics (excluding cost-utility analyses [CUAs]) are detailed in Table 1. Studies were conducted primarily in North America $(n=13)$ and Asia $(n=7)$, with two conducted in Europe. There were 17 retrospective studies, one prospective cohort study associated with a cost prediction model and four CUAs. The three most common sources of data were claims databases $(n=9)$, observational studies $(n=5)$, and CUAs $(n=4)$. The sources of data for the four CUAs were a national database [40] and information from the literature $[35,41,46]$. Diagnostic criteria differed between studies and were not always reported. Where reported, the American College of Rheumatology (ACR) classification criteria was used, as were combinations of diagnosis codes of the International Classification of Diseases, Ninth Revision, Clinical Modification (ICD-9-CM) and pathological classification from renal biopsy [48-50].

\section{Characteristics of patients with LN}

Patient characteristics were reported in 17 studies [26-34, 36, 38, 39, 42-45, 47]. The five studies not reporting patient characteristics were the four CUAs $[35,40,41,46]$ and one of the retrospective studies, which was only available as an abstract [37]. The included studies were primarily conducted in adults, with two studies conducted in children [32,33], and three did not have an age restriction $[29,30,34]$. Patients were predominantly (> 70\%) female.

Only four studies reported information on LN histological classification [28, 32, 36, 44]. Tse et al. [44] included only patients with Class IV, and Lateef et al. [36] included mainly patients with Class IV (57.1\%). Most patients included in the study by Guerra et al. [32] had Class IV or V (73.7\%) nephritis. Barbour et al. [28] stratified per-patient medication costs by LN class but did not report the proportions of patients in each class.

Only four studies reported LN activity $[26,29,32,46]$, one of which included only active patients [46]. One study included $37.6 \%$ active (defined as a SLE Disease Activity Index 2000 [SLEDAI-2 K] score > 6) and $18.4 \%$ inactive disease in patients with LN [26]. 


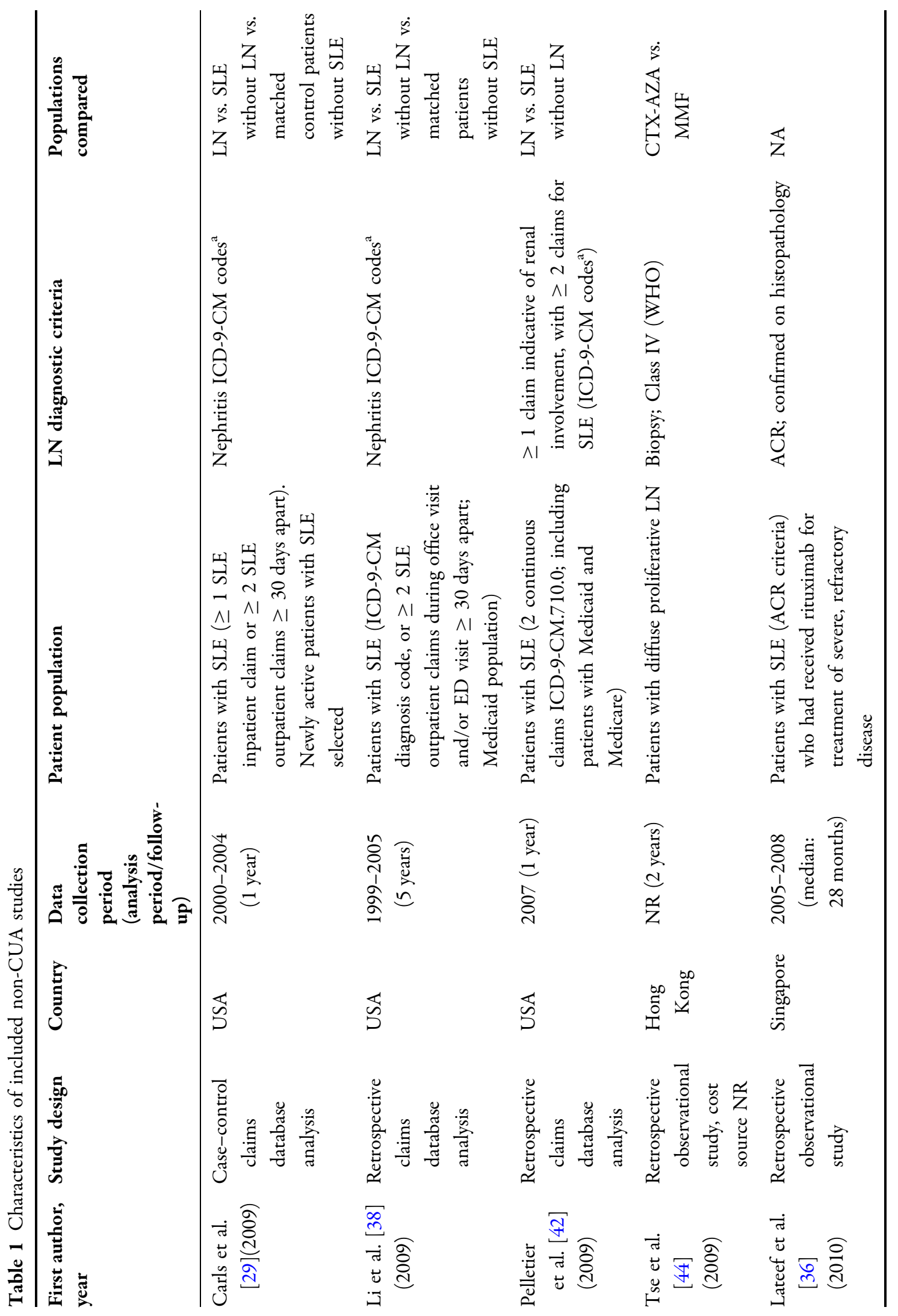




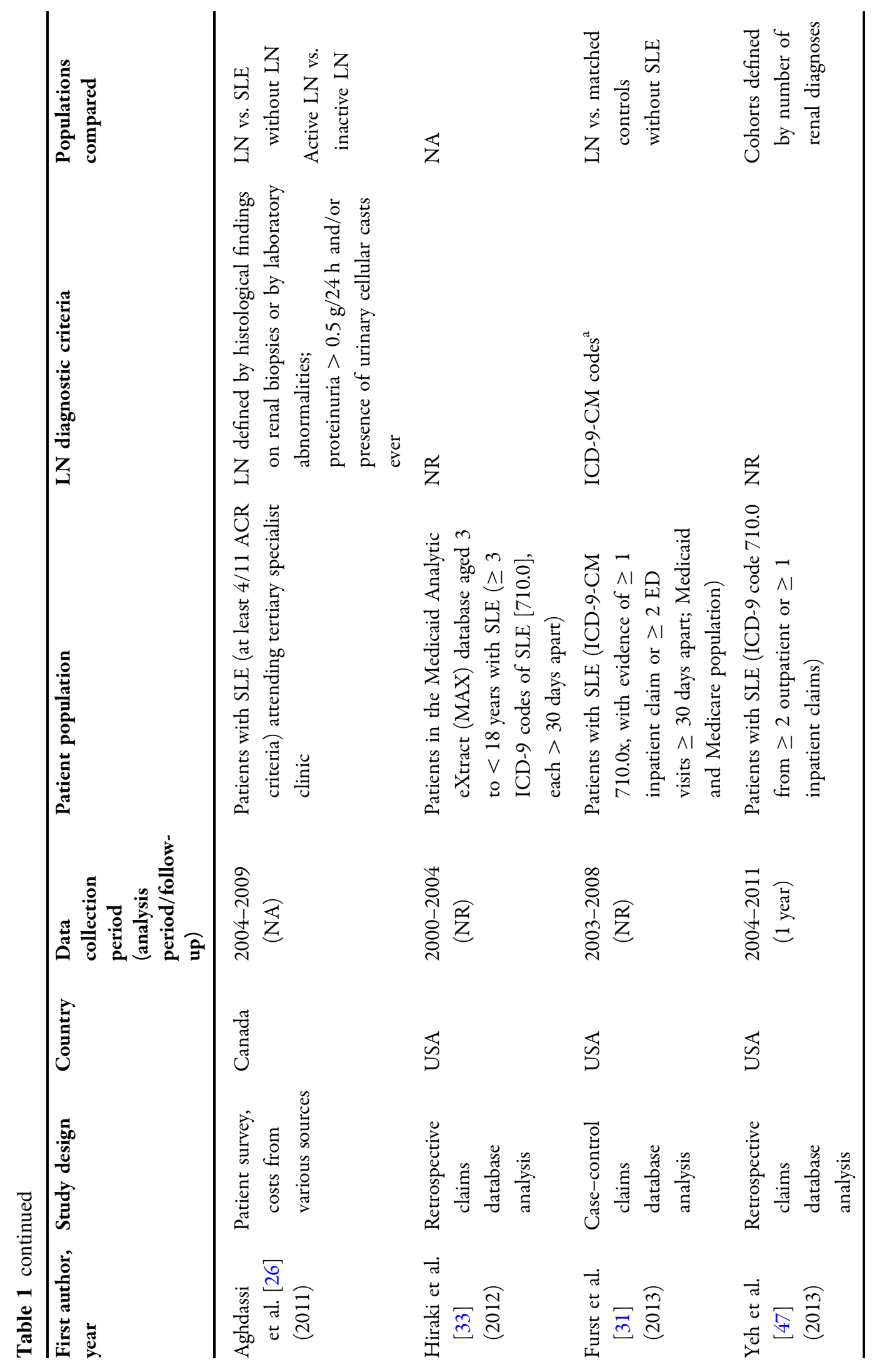




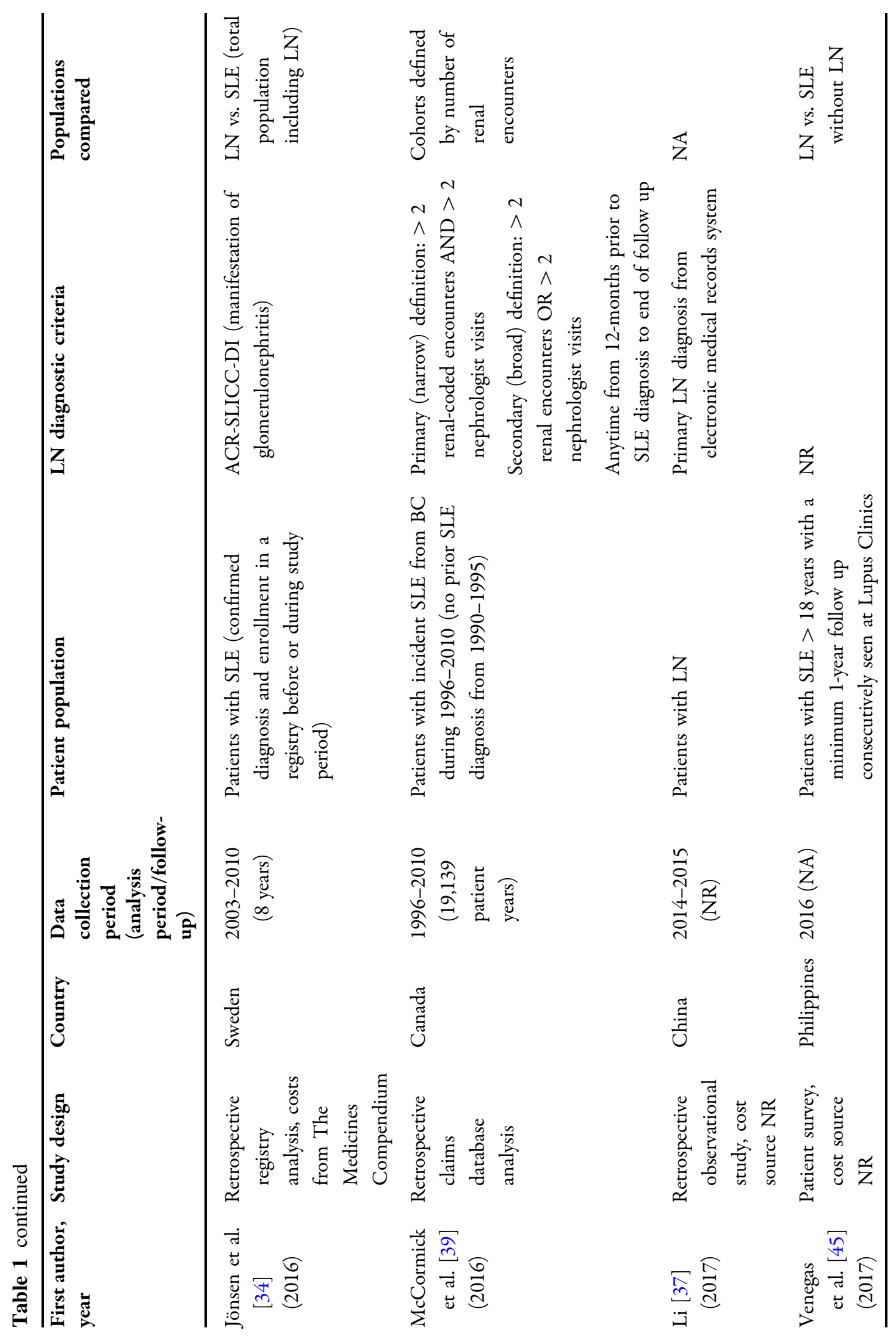




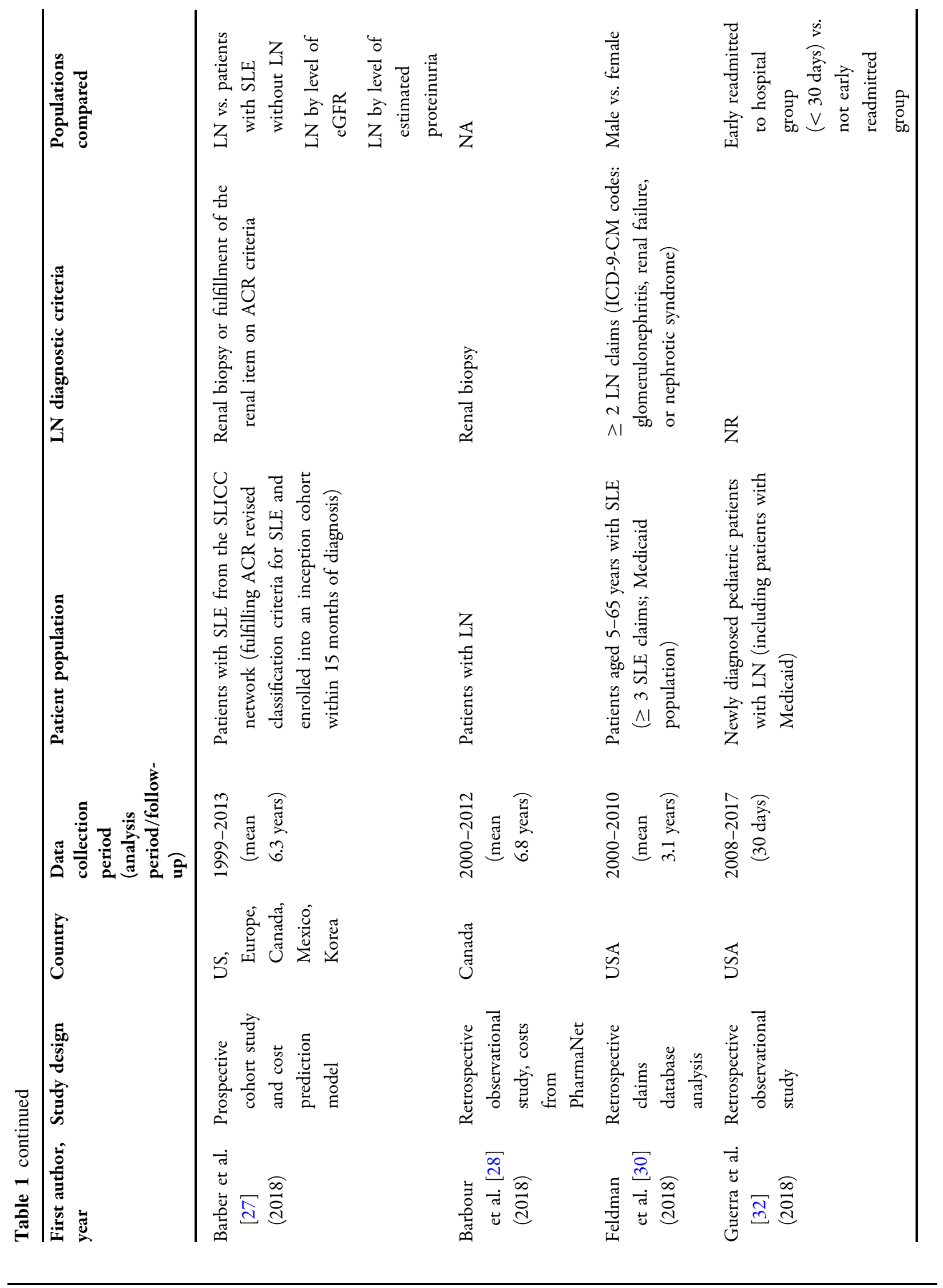




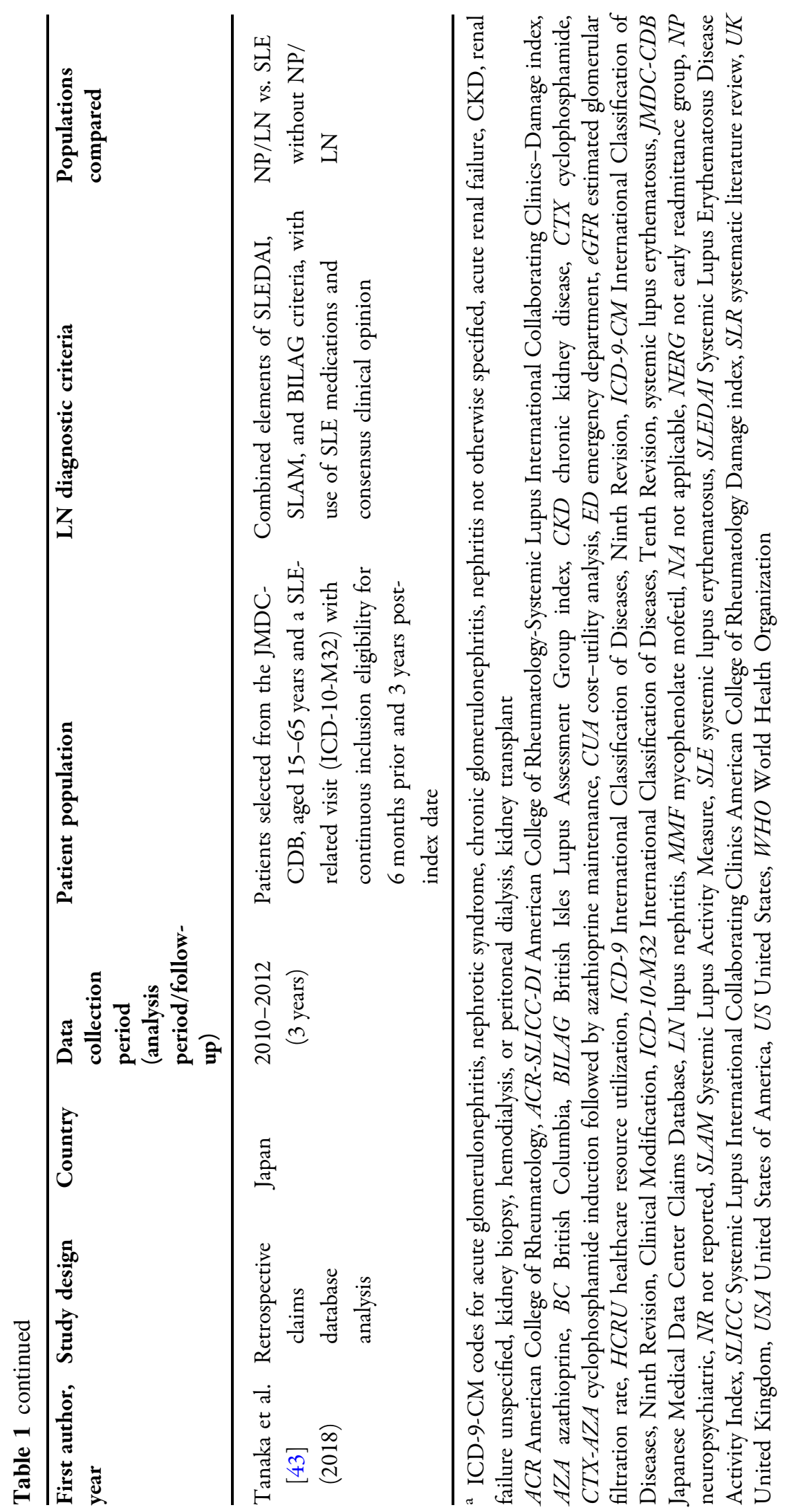


Few studies reported inclusion of patients with either CKD complications or ESKD. A Canadian study by Barbour et al. [28] and a US study by $\mathrm{Li}$ et al. [38] reported that $13.3 \%$ of patients with LN and $6.8 \%$ of patients with SLE had ESKD, respectively. A further US study by Feldman et al. [30] reported the 5-year cumulative incidence of ESKD to be $22.3 \%$ in males and $21.2 \%$ in females with $\mathrm{LN}$.

\section{Direct costs}

Direct costs reported in the identified studies included the cost of hospitalization, outpatient visits/services, emergency department (ED) visits, diagnostic tests, medications, alternative treatments, assistive devices, and surgical procedures (Table 2).

Total costs for LN [29, 31, 34, 38, 42, 43] were consistently higher than comparator populations; both patients without SLE $[29,31]$ and patients with SLE without LN (Table 2) [34, 38, 42, 43]. In two studies, the increase in total annual costs observed in the LN population versus the matched controls without SLE was significant $(p<0.001)[29,31]$. The total costs reported by Carls et al. [29] were higher than other claims studies conducted in the US. The authors hypothesized that expenditure was based on actual experience of patients rather than relying on national- or country-specific estimates based on negotiated fee schedules, which is often the case in other claims database analyses.

Two cost-analyses conducted in the US and Canada compared different algorithms to identify LN from claims databases $[39,47]$. In the US study [47], costs were higher with increased number of renal diagnoses (US\$33,176 with $\geq 1$ renal diagnosis, US\$38,883 with $\geq 3$ renal diagnoses plus $\geq 3$ nephrologist visits). Similarly, in the Canadian study [39], the more stringent LN definition of $>2$ renal-coded visits AND $>2$ nephrologist visits resulted in higher unadjusted mean per-patient-year costs for patients with LN than when LN was defined as $>2$ renal-coded visits OR $>2$ nephrologist visits (CA $\$ 85,292$ vs. CA $\$ 70,538$, respectively). These data indicate that the stringency of codes used to identify a patient with LN has an impact on the reported costs.
Two other Canadian studies stratified costs by LN classification and severity [27, 28]. Barbour et al. [28] reported a significant increase in annual per-patient total costs in patients with Class III or IV $( \pm$ V) LN disease (Year 2000: CA\$209, Year 2013: CA\$1592; 2016 CA\$; $p<0.001$ ). In patients with Class V LN alone, costs increased over the same time period, but this was not significant (CA $\$ 118, C A \$ 1002$; $p=0.016)$. Using prospectively collected data from the Systemic Lupus International Collaborating Clinics (SLICC) network inception cohort, Barber et al. [27] used a multistate Markov model to predict mean annual costs per patient in health states defined by the presence of LN and by either worsening estimated glomerular filtration rate (eGFR) or increasing estimated proteinuria. The model showed increasing costs in patients with LN and/or with worse renal function, versus those without LN or with eGFR $>60 \mathrm{ml} / \mathrm{min}$. Conversely, when Aghdassi et al. [26] compared patients with SLE with or without LN, and active (defined as a SLEDAI-2 K score $>6$ ) and inactive disease, there was no difference in annual costs between LN and patients with SLE without LN regardless of activity, but there was a significant difference in total annual costs between active and inactive $\mathrm{LN}(p<0.05)$.

In several studies, an increase in annual hospitalization costs was observed between patients with $\mathrm{LN}$ and their matched control patients without SLE, the total SLE population or patients with SLE without LN [29, 34, 42]. However, in a Canadian study by Aghdassi et al. [26], hospitalization costs were slightly higher for patients with SLE without LN compared with patients with $\mathrm{LN}$, and this difference was not significant.

No studies provided information about costs associated with renal flares specifically in patients with LN; however, Tanaka et al. [43] reported the cost of SLE flares (Table 2).

Costs for ESKD and its treatment were reported in six studies (Tables 2 and 3) $[27,35,38,40,41,45]$, three of which were CUAs $[35,40,41]$. In the US study by Li et al. [38], median annual medical costs for patients with SLE and ESKD increased by twofold between Year 1 and Year 5 (US\$33,827-66,490), whereas 


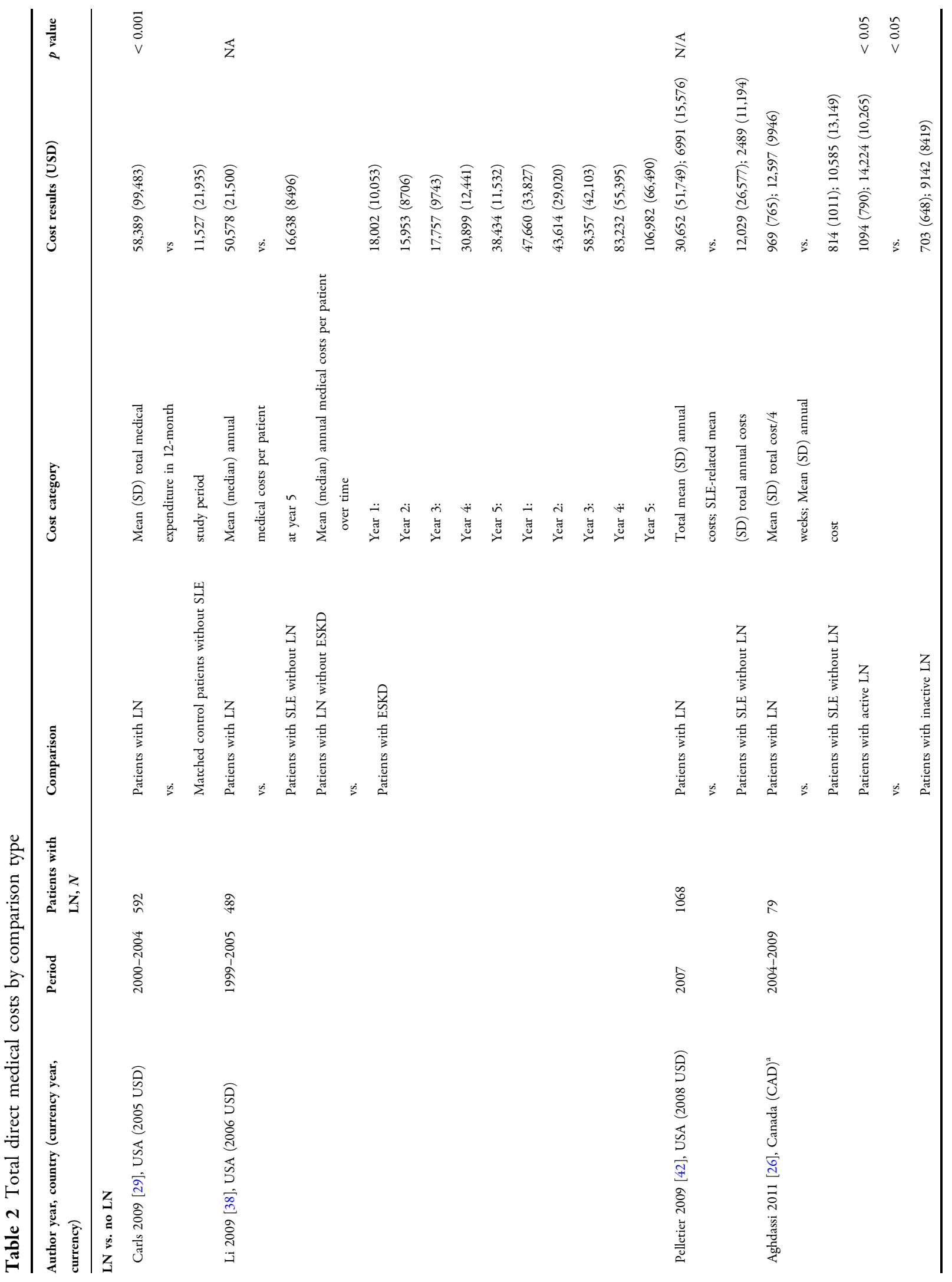




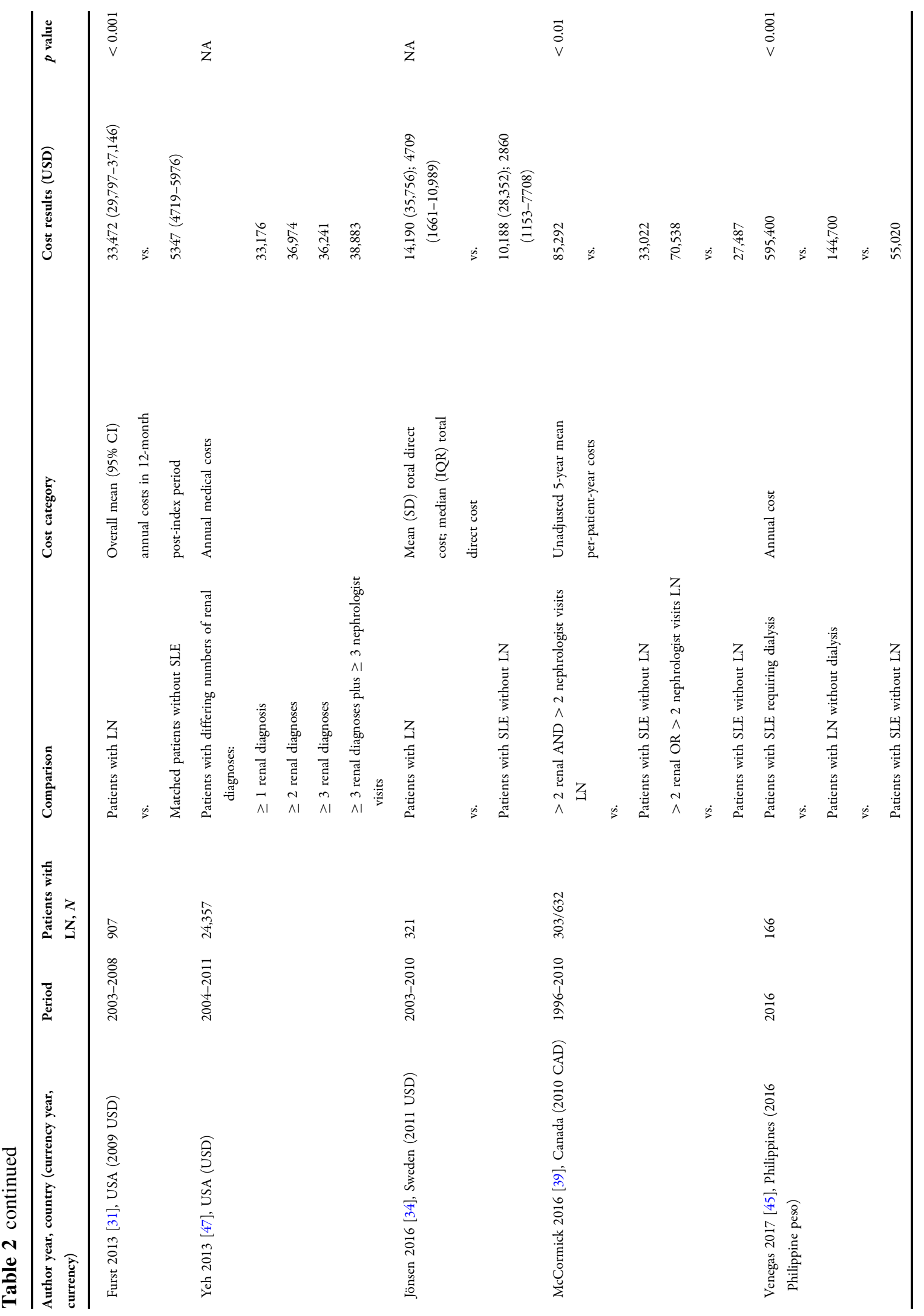




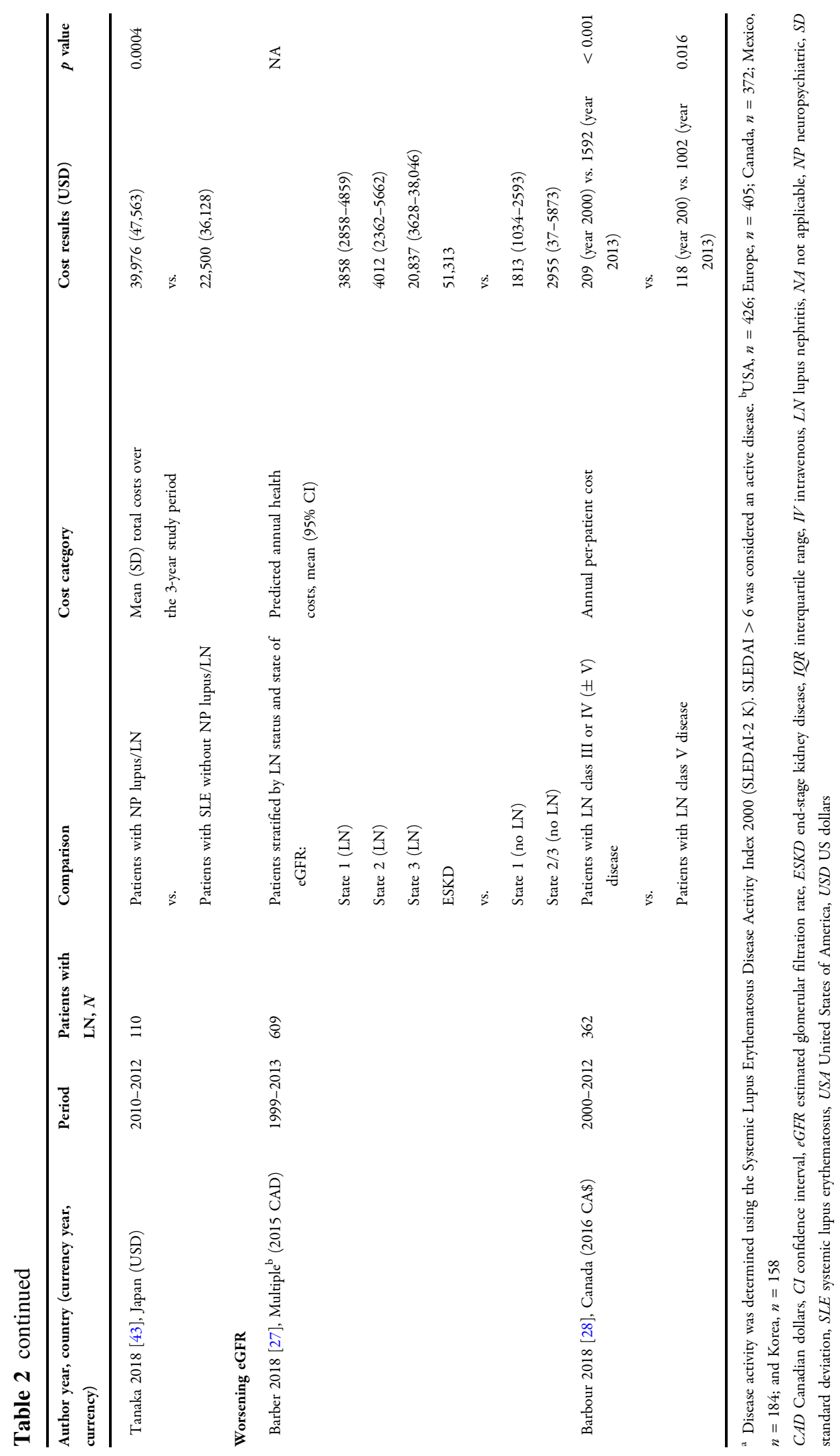


costs for patients with LN without ESKD increased by approximately 1.2 -fold in the same time period (US\$10,053-11,532). Similarly, Venegas et al. [45] found that treatment costs were significantly increased in patients with SLE requiring dialysis, versus patients with $\mathrm{LN}$ who did not require dialysis versus patients with SLE without LN (2016 Philippine peso 595,400 vs. 144,700 vs. 55,020 , respectively; $p<0.001$ ); ESKD was also found to be a significant independent contributor to treatment costs $(p<0.001)$. In addition, Barber et al. [27] reported that predicted mean annual costs related to ESKD were more than 17 -fold higher than health states reflecting good renal function.

\section{Indirect costs}

Indirect costs reported in the identified studies included the cost of absenteeism (absence from work), disability, and other loss of productivity (for patient and caregiver) (Table 4).

Four studies reported indirect costs, including cost of loss of productivity (for patient and caregiver) $[40,41]$, cost of absenteeism and short-term disability [29], and total indirect costs [34]. In the Swedish study by Jönsen et al. [34], although higher indirect costs were reported for the LN cohort compared with the total SLE cohort (mean [SD]: 2011 US\$25,094 $[31,387]$ vs. US\$23,181 [30,792]), the difference was not significant. Overall, no significant differences in indirect costs between patients with $\mathrm{LN}$ and comparators were reported (Table 4).

In the Canadian study by Aghdassi et al. [26], $48.1 \%$ of patients with $\mathrm{LN}$ versus $45.2 \%$ of patients with SLE without LN were employed. Of these, more patients with LN (56.8\%) missed work compared with patients with SLE without LN (42.9\%) and had more days of missed work in the past month (8.5 vs. 4.1 , respectively). Furthermore, caregivers of patients with LN missed more hours of work than those caring for patients with SLE without LN $(p<0.05)$.

\section{HCRU}

Overall, patients with $\mathrm{LN}$ required more inpatient, outpatient, and ED visits, were more likely to be hospitalized, spend longer in hospital, and need more medication than patients with SLE without LN or patients without SLE [26, 31, 38, 39, 42].

The mean annual numbers of inpatient, outpatient, and ED visits were higher for patients with LN (inpatient: 0.6-1.0, outpatient: 6.6-7.4, ED: 1.5-1.9) compared with the total SLE population (inpatient: 0.3-0.5, outpatient: 5.6-6.9, ED: 1.3-1.6) or patients without SLE (inpatient: 0.1-0.2, outpatient: $3.4-3.8$, ED: $0.5-0.9$ ) [31, 38, 42]. In addition, the mean annual numbers of inpatient, outpatient, and ED visits were higher in pediatric patients with LN (in the months prior to ESKD) (inpatient: 2.4, outpatient: 10.8, ED: 2.0) compared with adult patients with LN (inpatient: 0.6-1.0, outpatient: 6.6-7.4, ED: 1.5-1.9) [31, 33, 38]. Feldman et al. [30] reported that male patients with LN had fewer outpatient visits (incidence rate ratio [IRR], 95\% confidence interval $[95 \% \mathrm{CI}] 0.88,0.80-0.97)$ and fewer ED visits (IRR, 95\% CI 0.75, 0.63-0.90) than female patients with LN.

The proportion of patients reporting inpatient hospitalizations increased by 1.3-2.2 times in patients with LN compared with patients with SLE without LN [26, 38, 39, 42] and by 3.7-5.3 times compared with matched control patients without SLE [31, 38]. Pelletier et al. [42] also reported that patients with LN had longer lengths of stay compared with patients with SLE without LN (16.52 vs. 9.69 days, $p<0.001)$. However, this was not that case in the Canadian analysis by Aghdassi et al. [26] (2.8 vs. 5.7 days; $p \geq 0.05)$. Patients with active LN were more likely to be hospitalized than those with inactive LN (7.8 vs. $3.8 \%$ ), but patients with inactive LN spent longer in hospital than those with active LN (4.0 vs. 2.5 days). In a study conducted in Singapore, the length of hospitalization was significantly longer before versus after treatment with rituximab $(p=0.027)$ [36], while in an analysis conducted in Hong Kong, the duration of hospitalization was longer in patients with LN treated with sequential cyclophosphamide (CYC) induction followed by azathioprine maintenance compared with patients treated with mycophenolate mofetil (MMF) (mean [SD] 6.2 [18.2] vs. 1.1 [2.8] days) [44].

Over the 13-year period analyzed in Barbour et al. [28], the use of rituximab (from 0 to $3.5 \%$ ), 


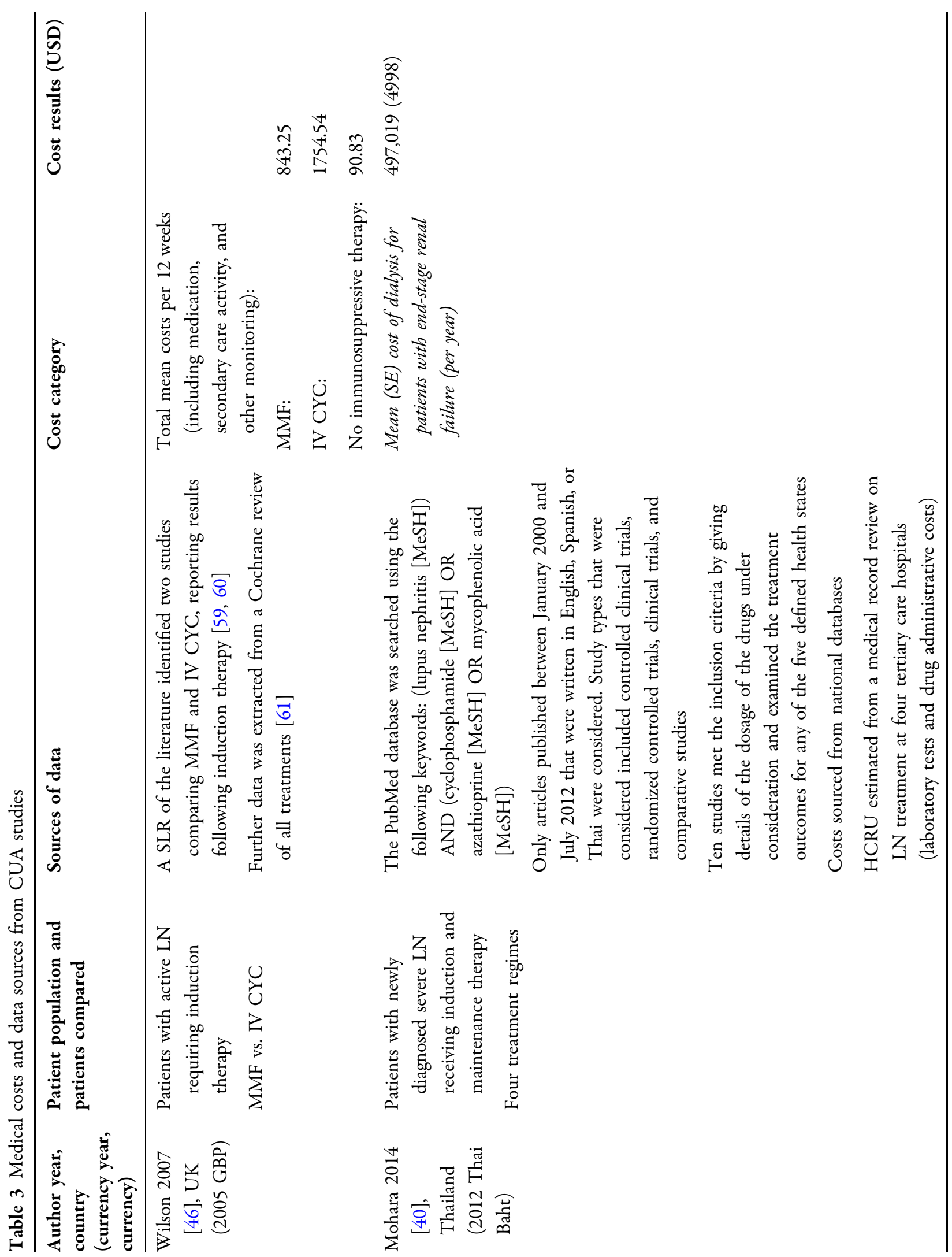




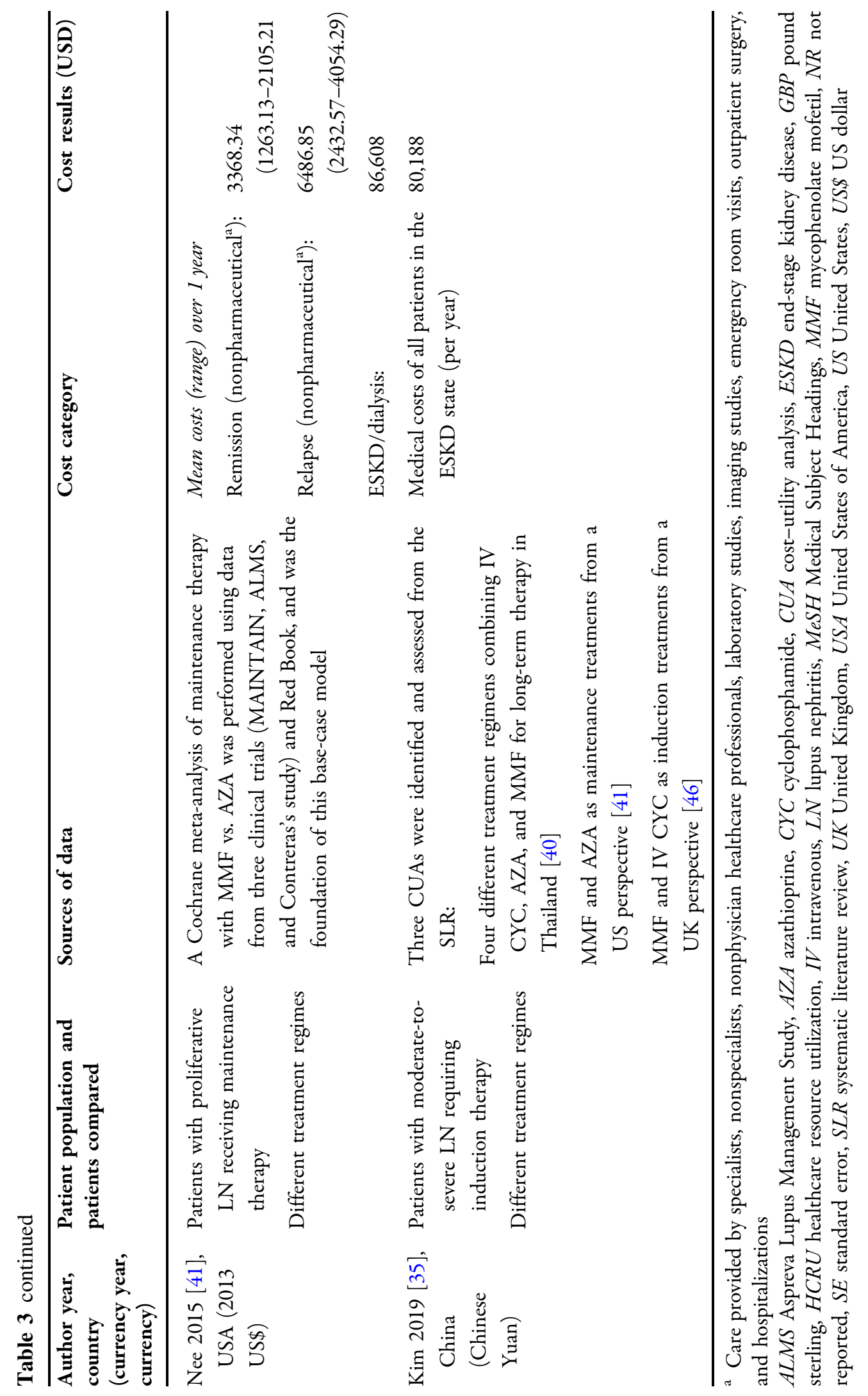


calcineurin inhibitor (from 0 to $4.5 \%$ ), and MMF (from 3.3 to 55.3\%) for treatment of LN all increased from the year 2000 to 2013. Patients with LN also averaged 128.6 more dispensed prescriptions than patients with SLE without LN over 5 years [39].

\section{DISCUSSION}

This SLR included 22 studies from 28 articles published between 2007 and 2019 that provided information on the cost and HCRU associated with LN.

LN was associated with substantially higher direct costs compared with patients without SLE or patients with SLE without LN $[26-29,31,34,37-39,42,43,45,47]$. Direct healthcare costs were 1.2-3.0 times greater in patients with LN versus patients with SLE without LN [26, 34, 38, 42, 43, 45]. As expected, differences were greater (5.1-6.3 times) when comparisons were made between patients with LN and matched control patients without SLE $[29,31]$

Costs for patients with ESKD were higher than for patients with $\mathrm{LN}$ who had not progressed to ESKD [38]. The need for dialysis significantly increased the cost of treatment (4.1 times) compared with patients with LN not requiring dialysis, and ESKD was a significant independent contributor to treatment costs [45]. In addition, Barber et al. [27] reported that increased costs were associated with worsening eGFR, with a marked increase among patients with $\mathrm{LN}$ reaching $<30 \mathrm{ml} / \mathrm{min}$ eGFR without ESKD. This trend is observed in studies of CKD due to other causes $[9,51]$, and reflects the importance of preventing any deterioration of renal function including prior to reaching kidney failure.

Barbour et al. [28] previously reported that costs of immunosuppressive treatments for glomerulonephritis were increasing over time due to changing patterns in clinical practice. In particular, the Aspreva Lupus Management Study (ALMS) reported pivotal data for LN treatment in 2009 and 2011, which likely consolidated the use of MMF as standard therapy for LN, especially in the US and Europe $[52,53]$.
These changes in clinical practice over the study period (2007-2019) may have influenced the direct costs of LN and make it more difficult to compare costs between studies.

Indirect costs were infrequently reported and no significant differences were observed between patients with LN and comparators $[29,34,40,41]$. Although SLE tends to affect patients during their most productive years of life, in terms of professional and familial achievement [1], there was limited information on the degree of productivity lost among patients with LN. Further research is also needed to understand the impact of $\mathrm{LN}$ on health-related quality of life and activities of daily living, which in turn may impact productivity. Only one of the studies included in this analysis reported limited data on absenteeism/presenteeism in LN [29], a substantial contributor to lost productivity among patients with SLE. A full understanding of indirect costs (notably productivity) is a particular gap in the literature and a future area of research.

In most of the included studies, patients with LN were more likely to be hospitalized and spend longer in hospital than their comparators [26, 31, 32, 39, 42, 43]. However, Aghdassi et al. [26] found that patients with SLE alone spent longer in hospitals than patients with active LN. This observation could be due to the more intensive treatment required for SLE, when extrarenal manifestations are severe, compared with LN. In addition, pediatric patients with LN (in the months prior to ESKD) were found to have more inpatient, outpatient, and ED visits than adult patients with LN [31, 33, 38]. This could suggest that pediatric patients would have higher HCRU costs than adult patients with LN.

Patients with LN were also more likely to require outpatient visits and a greater quantity of medication than their comparators $[26,28,31,38,42]$, particularly immunosuppressants and corticosteroids [42, 43]. As new treatments for LN emerge, it is important to understand the relationship between medication use and HCRU for cost-effectiveness studies. Evidence suggests that there is a cost-saving potential of earlier aggressive therapy to prevent disease progression. Despite the higher initial costs of biologics compared with standard 
Table 4 Indirect costs

\begin{tabular}{|c|c|c|c|}
\hline $\begin{array}{l}\text { Author, year, country } \\
\text { (currency year, currency) }\end{array}$ & Study details & Indirect cost category & Results \\
\hline \multirow[t]{8}{*}{$\begin{array}{l}\text { Carls } 2009 \text { [29] USA } \\
\text { (2005 USD) }\end{array}$} & $\begin{array}{l}\text { Case-control claims database } \\
\text { analysis, 2000-2004 }\end{array}$ & $\begin{array}{l}\text { Mean (SD) costs during 12-month } \\
\text { study period }\end{array}$ & \\
\hline & Age: LN vs. SLE: 44.4 vs. & $\mathrm{LN}$ & \\
\hline & $\begin{array}{l}47.1 \text { years } \\
n=592 \text { patients with LN }\end{array}$ & $\begin{array}{l}\text { Absenteeism }(n=10,70.0 \% \\
\text { claimed): }\end{array}$ & $\begin{array}{c}4781(10,144) \\
p=0.946\end{array}$ \\
\hline & & $\begin{array}{l}\text { Short-term disability }(n=20 \text {, } \\
15.0 \% \text { claimed }):\end{array}$ & $\begin{array}{c}1025(2673) \\
p=0.375\end{array}$ \\
\hline & & vs. & \\
\hline & & $\begin{array}{l}\text { Matched control patients without } \\
\text { SLE }\end{array}$ & \\
\hline & & $\begin{array}{l}\text { Absenteeism }(n=10,100 \% \\
\text { claimed): }\end{array}$ & $4552(2878)$ \\
\hline & & $\begin{array}{l}\text { Short-term disability }(n=20,5.0 \% \\
\text { claimed): }\end{array}$ & $386(1728)$ \\
\hline \multirow{4}{*}{$\begin{array}{l}\text { Mohara } 2014[40] \\
\text { Thailand (2012 Thai } \\
\text { Baht) }\end{array}$} & CUA/SLR & Productivity loss ${ }^{\mathrm{a}}$ of patient and & \\
\hline & & care giver per visit, mean (SE) & \\
\hline & & $\mathrm{LN}$ & $176(49)$ \\
\hline & & Major infection per episode & $5739(982)$ \\
\hline \multirow[t]{3}{*}{$\begin{array}{l}\text { Nee } 2015 \text { [41] USA (2013 } \\
\text { USD) }\end{array}$} & CUA/SLR & $\begin{array}{l}\text { 6-month/12-month mean costs of } \\
\text { productivity loss (range) due to: }\end{array}$ & \\
\hline & & Remission: & $\begin{array}{l}8033.19 / 16,066.38 \\
(6024.89-10,041.49)\end{array}$ \\
\hline & & Relapse: & $\begin{array}{l}8564.07 / 17,128.13 \\
(6423.05-10,705.09)\end{array}$ \\
\hline \multirow{4}{*}{$\begin{array}{l}\text { Jönsen } 2016 \text { [34] Sweden } \\
\text { (2011 USD) }\end{array}$} & Retrospective registry & Mean $(\mathrm{SD}) /$ median $(\mathrm{IQR})$ costs $^{\mathrm{c}}$ & \\
\hline & analysis, 2003-2010 & $\mathrm{LN}$ & $23,181(30,792) / 0$ \\
\hline & $\begin{array}{l}\text { SLE mean age at diagnosis } \\
\text { (range): } 35.4(3-85) \text { vears }\end{array}$ & vs. & $(0-44,543)$ \\
\hline & $n=321$ patients with $\mathrm{LN}$ & SLE & $\begin{array}{l}25,094(31,387) / 1255 \\
\quad(0-53,744)\end{array}$ \\
\hline
\end{tabular}

a Due to sick leave. ${ }^{b}$ Time lost from labor and non-labor (i.e., household work) market activity, plus the time that a caregiver spent helping the patient receiving healthcare services and the time the caregiver spent doing housework. ${ }^{\mathrm{B}}$ Based on sickness leave and disability pensions

$C I$ confidence interval, $C U A$ cost-utility analysis, IQR interquartile range, $L N$ lupus nephritis, $S D$ standard deviation, SE,standard error, SLE systemic lupus erythematosus, SLR systematic literature review, USA United States of America, USD United States dollars 
therapies, rituximab has been found to be cost saving in the treatment of $\mathrm{LN}$, as cost and number of hospitalizations are decreased after treatment [36].

This SLR has several limitations. As the search was performed in 2019 relevant recent publications could have been missed. For example, Padiyar et al. [54] has recently reported a comparison of the costs of oral CYC compared with intravenous CYC and Bell et al. [55] recently published an abstract reporting the burden of illness in LN; it was reported that patients with LN have significantly higher ambulatory visits, ED visits, hospitalizations, and costs than patients without SLE. Miyazaki et al. [56] also recently reported HCRU of patients with LN compared with patients without central nervous system (CNS) lupus or LN; a higher proportion of patients with $\mathrm{LN}$ had $\geq 1$ hospitalization compared with patients without CNS lupus or LN.

The method of LN case ascertainment also differed between the included studies. Nine of the 22 studies included in this SLR derived data from claims databases, which are inherently reliant on accurate coding of medical conditions. The identification of patients from administrative claims data, particularly if a disease does not have a specific ICD diagnostic code, necessitates the use of proxies for diagnosis. For example, diagnosis of LN was assumed if patients had concurrent codes for SLE and renal disease. Notably, two studies included in this review demonstrated that the increasing stringency of diagnosis code algorithms used to identify patients with $\mathrm{LN}$ resulted in an increase in the reported costs $[39,47]$.

In future studies, increased reporting of potential prognostic factors such as LN histological class and activity status would be useful, since a limited number of studies included in this analysis reported such information $[26,28,32,36,43,44,46]$. This highlights a gap in the literature as stratification of cost and HCRU by disease classification and/or severity would allow for a more comprehensive assessment of heterogeneity across studies, generalizability of conclusions, and quantitative synthesis.
In some studies, data were taken from claims databases of employed individuals, meaning patients not in work were not captured. This can introduce bias as analyses are consequently conducted on a "healthier" population with milder SLE who are able to work, rather than the general SLE population; this may particularly affect estimates generated for patients with LN given that it is the severe form of the disease. However, several studies using Medicare and Medicaid databases were also included in this study. Therefore, the potential bias introduced by claims databases may not have such an effect on this analysis.

In the US healthcare system, the cost of care for patients with ESKD is funded almost entirely by Medicare [38, 57]; hence, the costs associated with dialysis, kidney transplant, and associated medications will be underestimated by claims analyses that do not include all claims paid by Medicare. Given the high per-patient cost of dialysis and kidney transplant, this may have an important impact on the estimation of economic burden of LN.

As the search included in this study focused on the subgroup of patients with $\mathrm{LN}$, relevant aspects of economic burden borne by the broader SLE population, such as productivity losses, may not be reflected. For example, the claims data analysis by Garris et al. [58] was not included in the present SLR as cost data specific to an LN population was required to be included in the study.

The clear absence of data on the cost associated with a flare in SLE generally, but particularly with a renal flare, is a notable knowledge gap in the current literature. Although it is likely that the cost of flare is incorporated into other costs reported, without explicit data describing flare costs it is difficult to determine the immediate economic impact if these important clinical events can be avoided. Similarly, there are limited data available describing patients with LN with ESKD, with data used in published cost-effectiveness analyses coming from the general ESKD population rather than LN-related ESKD. As new interventions emerge for the treatment of active LN, greater delineation of these costs at the patient level will be critical to demonstrating their economic value. 


\section{CONCLUSIONS}

There is consensus across the studies included in this SLR that LN is expensive to manage. Specifically, LN was associated with higher direct costs (including total annual costs and costs of hospitalization and ESKD), total indirect costs, and HCRU (including hospitalization, outpatient services, and medication use) compared with those of either patients without SLE or patients with SLE without LN. However, limitations of current studies mean that it is difficult to determine the true cost of illness associated with LN. The greatest gap in the literature, which should be prioritized as a future research priority, is the absence of specific data for the cost of renal flare in patients with LN, despite it being a clinically important and frequently occurring medical emergency. As a disease flare is likely to result in a period of intense resource use for a patient with SLE, minimization of flare recurrence should reduce overall costs associated with $\mathrm{LN}$ disease control.

\section{ACKNOWLEDGEMENTS}

Funding. The study (GSK study 213531) was funded by GlaxoSmithKline (GSK). GSK commissioned Bridge Medical Consulting Ltd to conduct this SLR. The journal's Rapid Service was also funded by GSK.

Medical Writing and Editorial Assistance. Editorial support was provided by Helen Taylor, PhD, of Fishawack Indicia Ltd, UK, and was funded by GSK.

Authorship. All named authors meet the International Committee of Medical Journal Editors criteria for authorship for this article, take responsibility for the integrity of the work as a whole, and have given their approval for this version to be published.

Authorship Contributions. JCT, AM, and DAS were involved in the conception of the study, data acquisition, and analysis/ interpretation. KG was involved in the conception of the study and data analysis/ interpretation.

Disclosures. Juliette C. Thompson, Anadi Mahajan and David A. Scott are employees of Bridge Medical Consulting Ltd. Juliette C. Thompson and David A. Scott, are also employees of Visible Analytics Ltd. Kerry Gairy is an employee of GSK and holds stocks and shares in the company.

Compliance with Ethics Guidelines. This article is based on previously conducted studies and does not contain any studies with human participants or animals performed by any of the authors.

Data Availability. All data generated or analyzed during this study are available in this published article or as supplementary information files.

Open Access. This article is licensed under a Creative Commons Attribution-NonCommercial 4.0 International License, which permits any non-commercial use, sharing, adaptation, distribution and reproduction in any medium or format, as long as you give appropriate credit to the original author(s) and the source, provide a link to the Creative Commons licence, and indicate if changes were made. The images or other third party material in this article are included in the article's Creative Commons licence, unless indicated otherwise in a credit line to the material. If material is not included in the article's Creative Commons licence and your intended use is not permitted by statutory regulation or exceeds the permitted use, you will need to obtain permission directly from the copyright holder. To view a copy of this licence, visit http:// creativecommons.org/licenses/by-nc/4.0/.

\section{REFERENCES}

1. Nusbaum JS, Mirza I, Shum J, et al. Sex differences in systemic lupus erythematosus: epidemiology, 
clinical considerations, and disease pathogenesis. Mayo Clin Proc. 2020;95:384-94.

2. Grammer AC, Lipsky PE. B cell abnormalities in systemic lupus erythematosus. Arthritis Res Ther. 2003;5:S22-7.

3. Manson JJ, Rahman A. Systemic lupus erythematosus. Orphanet J Rare Dis. 2006;1:6.

4. Mahajan A, Amelio J, Gairy K, et al. Systemic lupus erythematosus, lupus nephritis and end-stage renal disease: a pragmatic review mapping disease severity and progression. Lupus. 2020;29:1011-20.

5. Galindo-Izquierdo M, Rodriguez-Almaraz E, PegoReigosa JM, et al. Characterization of patients with lupus nephritis included in a large cohort from the Spanish Society of Rheumatology Registry of Patients with Systemic Lupus Erythematosus (RELESSER). Medicine (Baltimore). 2016;95:e2891.

6. Hanly JG, O'Keeffe AG, Su L, et al. The frequency and outcome of lupus nephritis: results from an international inception cohort study. Rheumatology (Oxford). 2016;55:252-62.

7. Anders HJ, Saxena R, Zhao MH, Parodis I, Salmon JE, Mohan C. Lupus nephritis. Nat Rev Dis Primers. 2020;6:7.

8. Yap DY, Tang CS, Ma MK, Lam MF, Chan TM. Survival analysis and causes of mortality in patients with lupus nephritis. Nephrol Dial Transplant. 2012;27:3248-54.

9. Golestaneh L, Alvarez PJ, Reaven NL, et al. All-cause costs increase exponentially with increased chronic kidney disease stage. Am J Manag Care. 2017;23: S163-72.

10. Hermansen ML, Lindhardsen J, Torp-Pedersen C, Faurschou M, Jacobsen S. The risk of cardiovascular morbidity and cardiovascular mortality in systemic lupus erythematosus and lupus nephritis: a Danish nationwide population-based cohort study. Rheumatology (Oxford). 2017;56:709-15.

11. Zhu TY, Tam LS, Lee VW, Lee KK, Li EK. Systemic lupus erythematosus with neuropsychiatric manifestation incurs high disease costs: a cost-of-illness study in Hong Kong. Rheumatology (Oxford). 2009;48:564-8.

12. Fanouriakis A, Kostopoulou M, Cheema K, et al. 2019 Update of the Joint European League Against Rheumatism and European Renal AssociationEuropean Dialysis and Transplant Association (EULAR/ERA-EDTA) recommendations for the management of lupus nephritis. Ann Rheum Dis. 2020;79:713-23.
13. Tektonidou MG, Wang Z, Dasgupta A, Ward MM. Burden of Serious infections in adults with systemic lupus erythematosus: a national population-based study, 1996-2011. Arthritis Care Res (Hoboken). 2015;67:1078-85.

14. Slawsky KA, Fernandes AW, Fusfeld L, Manzi S, Goss TF. A structured literature review of the direct costs of adult systemic lupus erythematosus in the US. Arthritis Care Res (Hoboken). 2011;63:1224-32.

15. Meacock R, Dale N, Harrison MJ. The humanistic and economic burden of systemic lupus erythematosus: a systematic review. Pharmacoeconomics. 2013;31:49-61.

16. Turchetti G, Yazdany J, Palla I, Yelin E, Mosca M. Systemic lupus erythematosus and the economic perspective: a systematic literature review and points to consider. Clin Exp Rheumatol. 2012;30: S116-22.

17. Zhu TY, Tam LS, Lee VW, Lee KK, Li EK. The impact of flare on disease costs of patients with systemic lupus erythematosus. Arthritis Rheum. 2009;61: 1159-67.

18. Yeo AL, Koelmeyer R, Kandane-Rathnayake R, et al. Lupus low disease activity state and reduced direct health care costs in patients with systemic lupus erythematosus. Arthritis Care Res (Hoboken). 2020;72:1289-95.

19. Kan H, Guerin A, Kaminsky MS, et al. A longitudinal analysis of costs associated with change in disease activity in systemic lupus erythematosus. J Med Econ. 2013;16:793-800.

20. Panopalis P, Petri M, Manzi S, et al. The systemic lupus erythematosus Tri-Nation study: cumulative indirect costs. Arthritis Rheum. 2007;57:64-70.

21. Furie R, Rovin BH, Houssiau F, et al. Two-year, randomized, controlled trial of belimumab in lupus nephritis. N Engl J Med. 2020;383:1117-28.

22. Arriens C, Polyakova S, Adzerikho I, Randhawa S, Solomons N. OP0277 AURORA phase 3 study demonstrates voclosporin statistical superiority over standard of care in lupus nephritis (LN). Ann Rheum Dis. 2020;79(172):2-3.

23. Liberati A, Altman DG, Tetzlaff J, et al. The PRISMA statement for reporting systematic reviews and meta-analyses of studies that evaluate health care interventions: explanation and elaboration. PLoS Med. 2009;6:e1000100.

24. Moher D, Liberati A, Tetzlaff J, Altman DG, Group P. Preferred reporting items for systematic reviews and meta-analyses: the PRISMA statement. PLoS Med. 2009;6:e1000097. 
25. Cochrane Handbook for Systematic Reviews of Interventions. 2020. Available from: https:// training.cochrane.org/handbook/current. Accessed 8 Oct 2020

26. Aghdassi E, Zhang W, St-Pierre Y, et al. Healthcare cost and loss of productivity in a Canadian population of patients with and without lupus nephritis. J Rheumatol. 2011;38:658-66.

27. Barber MRW, Hanly JG, Su L, et al. Economic evaluation of lupus nephritis in the Systemic Lupus International Collaborating Clinics Inception cohort using a multistate model approach. Arthritis Care Res (Hoboken). 2018;70:1294-302.

28. Barbour S, Lo C, Espino-Hernandez G, et al. The population-level costs of immunosuppression medications for the treatment of glomerulonephritis are increasing over time due to changing patterns of practice. Nephrol Dial Transplant. 2018;33:626-34.

29. Carls G, Li T, Panopalis P, et al. Direct and indirect costs to employers of patients with systemic lupus erythematosus with and without nephritis. J Occup Environ Med. 2009;51:66-79.

30. Feldman $\mathrm{CH}$, Broder A, Guan $\mathrm{H}$, Yazdany J, Costenbader KH. Sex differences in health care utilization, end-stage renal disease, and mortality among Medicaid beneficiaries with incident lupus nephritis. Arthritis Rheumatol. 2018;70:417-26.

31. Furst DE, Clarke A, Fernandes AW, et al. Medical costs and healthcare resource use in patients with lupus nephritis and neuropsychiatric lupus in an insured population. J Med Econ. 2013;16:500-9.

32. Guerra AAH, Prahalad S, Rouster-Stevens KA, Garro R, Bryan L, Hong Y. Readmission rate within 30 days of hospitalization due to new onset lupus nephritis and associated risk factors: The importance of intravenous pulse methylprednisolone therapy. Arthritis Rheumatol. 2018;70:abstract 459.

33. Hiraki LT, Feldman CH, Alarcon GS, et al. Variation in healthcare utilization by region and number of rheumatologists per state among pediatric Medicaid patients with lupus nephritis prior to end-stage renal disease in the United States, 2000-2004. Arthritis Rheum. 2012;64:S125.

34. Jönsen A, Hjalte F, Willim M, et al. Direct and indirect costs for systemic lupus erythematosus in Sweden. A nationwide health economic study based on five defined cohorts. Semin Arthritis Rheum. 2016;45:684-90.

35. Kim S, Reen Ooi AY, Stephens T, Jiang H. Cost-effectiveness of tacrolimus for the treatment of moderate-to-severe lupus nephritis in China. J Comp Eff Res. 2019;8:1125-41.

36. Lateef A, Lahiri M, Teng GG, Vasoo S. Use of rituximab in the treatment of refractory systemic lupus erythematosus: Singapore experience. Lupus. 2010;19:765-70.

37. Li T. The pharmacotherapeutic pattern of lupus nephritis patients and its effect on the hospitalisation cost in China. Lupus Sci Med. 2017;4:A81.

38. Li T, Carls GS, Panopalis P, Wang S, Gibson TB, Goetzel RZ. Long-term medical costs and resource utilization in systemic lupus erythematosus and lupus nephritis: a five-year analysis of a large Medicaid population. Arthritis Rheum. 2009;61:755-63.

39. McCormick N, Marra C, Avina-Zubieta A. 220 Longitudinal, incremental direct medical costs of lupus nephritis amongst a general population-based cohort of systemic lupus erythematosus. J Rheumatol. 2016;43:1234.

40. Mohara A, Perez Velasco R, Praditsitthikorn N, Avihingsanon Y, Teerawattananon Y. A cost-utility analysis of alternative drug regimens for newly diagnosed severe lupus nephritis patients in Thailand. Rheumatology (Oxford). 2014;53:138-44.

41. Nee R, Rivera I, Little DJ, Yuan CM, Abbott KC. Cost-Utility Analysis of Mycophenolate Mofetil versus Azathioprine Based Regimens for Maintenance Therapy of Proliferative Lupus Nephritis. Int J Nephrol. 2015;2015:917567.

42. Pelletier EM, Ogale S, Yu E, Brunetta P, Garg J. Economic outcomes in patients diagnosed with systemic lupus erythematosus with versus without nephritis: results from an analysis of data from a US claims database. Clin Ther. 2009;31:2653-64.

43. Tanaka Y, Mizukami A, Kobayashi A, Ito C, Matsuki T. Disease severity and economic burden in Japanese patients with systemic lupus erythematosus: a retrospective, observational study. Int J Rheum Dis. 2018;21:1609-18.

44. Tse KC, Tang CS, Lam MF, Yap DY, Chan TM. Cost comparison between mycophenolate mofetil and cyclophosphamide-azathioprine in the treatment of lupus nephritis. J Rheumatol. 2009;36:76-81.

45. Venegas E, Geslani K, Navarra S. 426 Renal activity and damage incur highest medical costs among Filipino patients with systemic lupus erythematosus. Lupus Sci Med. 2017;4:A203-4.

46. Wilson EC, Jayne DR, Dellow E, Fordham RJ. The cost-effectiveness of mycophenolate mofetil as firstline therapy in active lupus nephritis. Rheumatology (Oxford). 2007;46:1096-101. 
47. Yeh WS, Clark DW, McCarty KM. Health resource utilization of lupus nephritis patients-a comparison of result across case identification algorithms. Value Health. 2013;16:A21.

48. Hahn BH, McMahon MA, Wilkinson A, et al. American College of Rheumatology guidelines for screening, treatment, and management of lupus nephritis. Arthritis Care Res (Hoboken). 2012;64: 797-808.

49. International Classification of Diseases, Ninth Revision, Clinical Modification (ICD-9-CM). 2015. Available from: https://www.cdc.gov/nchs/icd/ icd9cm.htm. Accessed 8 Apr 2021

50. Weening JJ, D'Agati VD, Schwartz MM, et al. The classification of glomerulonephritis in systemic lupus erythematosus revisited. Kidney Int. 2004;65: 521-30.

51. Honeycutt AA, Segel JE, Zhuo X, Hoerger TJ, Imai K, Williams D. Medical costs of CKD in the Medicare population. J Am Soc Nephrol. 2013;24:1478-83.

52. Appel GB, Contreras G, Dooley MA, et al. Mycophenolate mofetil versus cyclophosphamide for induction treatment of lupus nephritis. J Am Soc Nephrol. 2009;20:1103-12.

53. Dooley MA, Jayne D, Ginzler EM, et al. Mycophenolate versus azathioprine as maintenance therapy for lupus nephritis. N Engl J Med. 2011;365: 1886-95.

54. Padiyar S, Arya S, Surin A, Viswanath V, Danda D. Comparison of safety, efficacy and cost between oral pulse cyclophosphamide versus intravenous cyclophosphamide pulse therapy in severe systemic lupus erythematosus. Int J Rheum Dis. 2020;23: 800-4.

55. Bell CF, Wu B, Xie B, et al. Burden of illness of lupus nephritis in patients with systemic lupus erythematosus. J Am Soc Nephrol. 2020;31:553.

56. Miyazaki C, Sruamsiri R, Mahlich J, Jung W. Treatment patterns and medical cost of systemic lupus erythematosus patients in Japan: a retrospective claims database study. J Med Econ. 2020;23:786-99.

57. Eggers PW. Medicare's end stage renal disease program. Health Care Financ Rev. 2000;22:55-60.

58. Garris C, Jhingran P, Bass D, Engel-Nitz NM, Riedel A, Dennis G. Healthcare utilization and cost of systemic lupus erythematosus in a US managed care health plan. J Med Econ. 2013;16:667-77.

59. Ong LM, Hooi LS, Lim TO, et al. Randomized controlled trial of pulse intravenous cyclophosphamide versus mycophenolate mofetil in the induction therapy of proliferative lupus nephritis. Nephrology (Carlton). 2005;10:504-10.

60. Ginzler EM, Dooley MA, Aranow C, et al. Mycophenolate mofetil or intravenous cyclophosphamide for lupus nephritis. $\mathrm{N}$ Engl J Med. 2005;353:2219-28.

61. Flanc RS, Roberts MA, Strippoli GF, Chadban SJ, Kerr PG, Atkins RC. Treatment for lupus nephritis. Cochrane Database Syst Rev. 2004;2004:002922. 